\title{
Experimental Determination of Glauconite Dissolution Kinetics
}

\author{
Q.ZHANG ${ }^{1 *}$, M. NightingALE ${ }^{1}$ AND B.M. TUTOLO ${ }^{1}$ \\ ${ }^{1}$ University of Calgary Department of Geoscience, 2500 \\ University Dr. NW Calgary AB, T2N 1N4, Canada. \\ (*corresponding author: qin.zhang1@ucalgary.ca)
}

Geological carbon storage (GCS) has been proposed as an important way to actively reduce $\mathrm{CO}_{2}$ emissions into the atmosphere and potentially avoid the most catastrophic effects of anthropogenic climate change. In situ carbon mineralization provoked by injecting captured $\mathrm{CO}_{2}$ into reactive rocks has the potential to permanently store large volumes of carbon in the subsurface [e.g., 1]. Although much of this work has focused on igneous rocks such as basalts and peridotite, glauconite, an authigenic, iron-rich clay mineral that is abundant in marine greensands formations globally, shows significant promise for in situ carbonation reactions in sedimentary rocks. Greensands formations commonly show evidence of glauconite dissolution and coupled siderite precipitation during diagenesis, and this reaction could be enhanced by $\mathrm{CO}_{2}$ injection during GCS.

Although numerous geochemical studies have attempted to predict the potential for glauconite carbonation as a GCS mechanism, this work has invariably suffered from the almost completely unconstrained rates of glauconite dissolution under relevant conditions. To fill this significant knowledge gap, we have undertaken a study to quantify the rates of glauconite dissolution. We developed a new, mixed-flow reactor apparatus to explore the kinetics of glauconite dissolution under strictly controlled anaerobic conditions at $\mathrm{pH}$ ranging from 1 to 8 and temperatures ranging from 24 to $60{ }^{\circ} \mathrm{C}$. Temporal evolution of the differences between the inlet and outlet solution aqueous cation concentrations during glauconite dissolution experiments have been analyzed using inductively coupled plasma-optical emission spectrometry (ICP-OES). BET surface area-normalized rates exhibit stoichiometric or close-to-stoichiometric glauconite dissolution for all elements except for Al. The kinetic data we present will provide a vital first step in the development of quantitative reactive-transport models to predict the fate of $\mathrm{CO}_{2}$ in glauconite-bearing GCS reservoirs.

[1] Snæbjörnsdóttir et al. (2020) Nature Reviews Earth \& Environment 1-13. 